\title{
Analisis Perbaikan Postur Kerja dengan Cornell Musculoskeletal Discomfort Questionnaires (CMDQ) dan Metode Rapid Entire Body Assesment (REBA) Beban Fisik Pekerja Konstruksi (Studi Kasus: Pembangunan Jembatan Mlowo, Cs Nguter Sukoharjo)
}

\author{
Sri Hartanti ${ }^{1 *}$, Maria Puspita Sari ${ }^{2}$ \\ ${ }^{1,2}$ Teknik Industri, Universitas Veteran Bangun Nusantara, Sukoharjo, Indonesia
}

(*artanti473@gmail.com )

\begin{abstract}
Abstrak - Proyek konstruksi memiliki tekanan bagi para pekerja, sehingga memicu kelelahan, penyakit akibat kerja, sehingga menurunkan produktivitas. Pekerja melakukan penanganan material yang tidak tepat menggunakan Manual Material Handling, menyebabkan pekerja mengalami nyeri pada bagian tubuh. Otot para pekerja menerima beban statis terus-menerus dalam jangka waktu lama berpotensi mengakibatkan gangguan muskuloskeletal. Tujuan penelitian untuk menganalisis postur kerja para pekerja proyek konstruksi pembangunan Jembatan Mlowo, Cs Nguter Sukoharjo. Penelitian ini menggunakan metode penelitian eksperimental di lokasi proyek, kemudian dianalisis menggunakan kuesioner CMDQ dan metode $R E B A$. Terdapat 7 aktivitas yang dianalisis dalam penelitian ini, sebab memiliki tingkat risiko tinggi dan dilakukan berulang, antara lain aktivitas penulangan, pemindahan baja tulangan, pengecoran (menahan bak penuang cor), pemasangan bagesting, pengecoran (mengalirkan cor), pemindahan girder, dan pemindahan las listrik. Hasil penelitian menunjukkan bahwa semua aktivitas memerlukan proses perbaikan. Berdasarkan kuesioner CMDQ, bagian tubuh yang sering dirasakan nyeri oleh pekerja adalah lengan atas. Penilaian dengan REBA, penulangan skor 7 (perlu perbaikan), pemindahan baja tulangan skor 10 (harus segara perbaikan), pengecoran (menahan bak) skor 11 (saat ini dilakukan perbaikan), pemasangan bagesting skor 7 (perlu perbaikan), mengalirkan pengecoran skor 9 (segera perbaikan), pemindahan girder skor 12 (perbaikan saat ini), dan pemindahan las listrik skor 10 (segera perbaikan).
\end{abstract}

Kata kunci: kelelahan; muskuloskeletal; $R E B A$

\section{PENDAHULUAN}

Proyek adalah aktivitas yang diorganisasikan menggunakan anggaran dana serta sumber daya untuk diselesaikan dalam jangka waktu tertentu. Salah satu proyek dengan batasan waktu adalah proyek konstruksi. Proyek konstruksi memiliki tekanan bagi para pekerjanya, antara lain batasan waktu, biaya dan mutu (Messah et al., 2013). Hal ini memicu kelelahan bagi para pekerja konstruksi. Kelelahan merupakan masalah krusial pekerja konstruksi karena dapat menghilangkan kecakapan kerja bahkan memicu kecelakaan kerja (Verawati, 2017). Kelelahan kerja dalam jangka waktu yang lama juga akan menyebabkan penyakit akibat kerja karena beban kerja berlebih, sehingga dapat mempengaruhi performansi kerja dan bisa berdampak pada penurunan produktivitas (Fathimahhayati et al., 2019).

Penelitian ini mengambil studi kasus pekerja proyek konstruksi pembangunan Jembatan Mlowo, Cs (Jembatan Nguter Sukoharjo). Para pekerja melakukan penanganan material secara tidak tepat yaitu menggunakan Manual Material Handling $(M M H)$. Hal ini dilakukan secara berulang menyebabkan pekerja mengalami nyeri pada bagian tubuh, dan beresiko tinggi cidera. Salah satunya adalah gangguan muskuloskeletal, yaitu keluhan yang berada pada bagian otot skeletal atau otot rangka yang dirasakan oleh pekerja mulai dari keluhan sangat ringan hingga sangat sakit. Pada penelitian sebelumnya ditemukan hampir 25\% kecelakaan kerja di Indonesia diakibatkan oleh MMH. Rata-rata pekerja mengalami cedera pada tulang belakangnya (PT Safety Sign Indonesia, 2018).

Gangguan muskuloskeletal saat ini mengalami peningkatan kasus. Sekitar 34\% dari total hari kerja hilang karena cedera atau sakit yang ditimbulkan oleh keluhan muskuloskeletal. Hal ini mengakibatkan permasalahan berkelanjutan, salah satunya memerlukan biaya kompensasi sebesar 15 sampai 20 miliar dolar US (Internasional Labor Organization, 2014). Grafik tingginya angka kecelakaan kerja disajikan pada Gambar 1. 


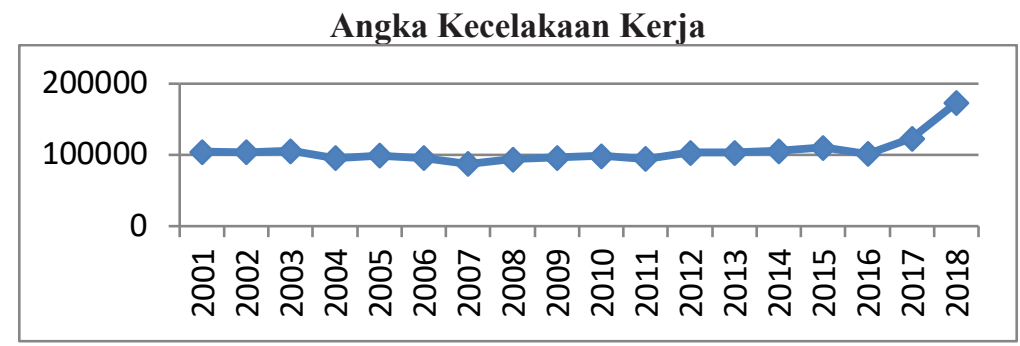

Gambar 1. Grafik angka kecelakaan kerja

Dari jumlah kasus yang dilaporkan dapat diketahui bahwa sekitar 32\% mengalami cedera muskuloskeletal akibat aktivitas kerja (Tjahayuningtyas, 2019).

Jangka waktu pembangunan Jembatan Mlowo, Cs (Jembatan Nguter Sukoharjo) selama 9 bulan. Otot para pekerja menerima beban statis dalam jangka waktu lama sehingga menyebabkan keluhan pada sendi, ligamen dan tendon (Hasrianti, 2016). Para pekerja sering mengeluhkan rasa nyeri pada bagian punggung, leher, kaki, lengan atas, lengan bawah, dan pergelangan tangan.

Penelitian ini dimaksudkan untuk menjawab permasalahan mengenai level risiko dan analisis tingkat urgensi risiko postur kerja pada faal tubuh pekerja konstruksi. Tujuan penelitian ini adalah menganalisis postur kerja para pekerja proyek konstruksi pembangunan Jembatan Mlowo, Cs Nguter Sukoharjo. Penelitian ini bermanfaat bagi pekerja, kontraktor, maupun pemerintah. Antara lain menurunkan risiko Work-Related Musculoskeletal Disorder (WMSDs), inovasi perbaikan postur kerja bagi para pekerja proyek konstruksi, menurunkan potensi kecelakaan kerja, mengurangi biaya kompensasi, serta memberikan solusi mengenai metode pengendalian pengerjaan konstruksi yang memenuhi standar.

\section{STUDI LITERATUR}

\section{A. Studi Literatur}

Berbagai penelitian telah dilakukan mengenai analisis perbaikan postur kerja dengan kuesioner $C M D Q$ dan Metode Rapid Entire Body Assesment (REBA), yang disajikan pada Tabel 2:

Tabel 2

Rangkuman studi literatur

\begin{tabular}{|c|c|c|c|c|}
\hline No & $\begin{array}{l}\text { Peneliti } \\
\text { (tahun) }\end{array}$ & Judul & Metode Analisis & Hasil/Kesimpulan \\
\hline 1 & $\begin{array}{l}\text { Widodo et } \\
\text { al., (2017) }\end{array}$ & $\begin{array}{l}\text { Analisis Beban Kerja dan } \\
\text { Keluhan Subjektif Pekerja } \\
\text { serta Usulan Perbaikan pada } \\
\text { Proses Pembuatan Batako }\end{array}$ & $\begin{array}{l}\text { Analisis pekerja } \\
\text { menggunakan } \\
\text { kuesioner Nordic } \\
\text { Body Map dan } \\
\text { REBA }\end{array}$ & $\begin{array}{l}\text { Pekerja pembuat batako basah memiliki nilai } 11 \\
\text { yaitu beresiko sangat tinggi. Setelah perbaikan } \\
\text { terjadi penurunan nilai menjadi } 6 \text { yaitu resiko } \\
\text { sedang, keluhan pekerja pada pinggang dan tangan } \\
\text { kanan tidak dirasakan kembali }\end{array}$ \\
\hline 2 & $\begin{array}{l}\text { Pratam et } \\
\text { al., (2013) }\end{array}$ & $\begin{array}{lr}\text { Identifikasi Risiko Ergonomi } \\
\text { Dengan Metode Quick } \\
\text { Exposure Check dan } \\
\text { Nordicbody Map }\end{array}$ & $\begin{array}{lr}\text { Analisis } & \text { pekerja } \\
\text { dengan } & \text { metode } \\
\text { Quick Exposure } & \text { Check r dan } \\
\text { Nordicbody Map }\end{array}$ & $\begin{array}{l}\text { Mengindikasikan bahwa pekerjaan dikategorikan } \\
\text { kurang aman. Terdapat keluhan pada bagian leher, } \\
\text { punggung, pantat, bahu, lengan, tangan dan } \\
\text { pergelangan tangan. Sehingga perlu perbaikan, atau } \\
\text { rawan terkena MSDs. }\end{array}$ \\
\hline 3 & $\begin{array}{l}\text { (Pratama et } \\
\text { al., 2019) }\end{array}$ & $\begin{array}{l}\text { Analisis Postur Kerja } \\
\text { Menggunakan Rapid Office } \\
\text { Strain Assessmentdan } \\
\text { CMDQ pada PT XYZ }\end{array}$ & $\begin{array}{l}\text { Kuesioner CMDQ } \\
\text { dan Metode ROSA }\end{array}$ & $\begin{array}{l}\text { Hasil kuesioner CMDQ menunjukan keluhan pada } \\
\text { leher, punggung bawah, dan pinggul/pantat. } \\
\text { Berdasarkan hasil final score ROSA, diketahui } \\
\text { bahwa operator tergolong dalam klasifikasi } \\
\text { Warning Level atau rawan terkena MSDs. }\end{array}$ \\
\hline
\end{tabular}

Terdapat perbedaan dengan penelitian sebelumnya, yaitu pada metode yang digunakan. Penelitian ini dilakukan analisis melalui hasil kuesioner $C M D Q$, kemudian dilakukan pengukuran dengan metode REBA untuk meningkatkan keakuratan. Sehingga dapat digunakan untuk pengambilan keputusan pengadaan perbaikan postur kerja agar tidak terjadi keluhan muskuloskeletal pada tubuh pekerja. 


\section{B. Postur Kerja}

Merupakan proses kerja yang sesuai dengan anatomi tubuh dan ukuran peralatan yang digunakan pada saat bekerja. Postur kerja yang tidak sesuai dapat mengakibatkan keluhan muskuloskeletal (Suryadi \& Rachmawati, 2020).

\section{Keluhan Muskuloskeletal}

Merupakan nyeri dari sistem muskuloskeletal yang meliputi tulang, sendi dan jaringan lunak pendukung, disebabkan oleh postur kerja, kondisi tempat kerja, faktor individu dan faktor psikososial (Dewi, 2017).

\section{Cornell Musculoskeletal Discomfort Questionnaires (CMDQ)}

Merupakan alat ukur subjektif berupa kuesioner pemetaan bagian tubuh yang dirasa mengalami sakit dalam bekerja, dengan tambahan pertanyaan tentang prevalensi nyeri muskuloskeletal, tingkat keparahan, dan akibatnya terhadap kinerja responden (Pratama et al., 2019). Data yang diperoleh lalu dilakukan perkalian, sehingga didapatkan nilai $C M D Q$. Nilai $C M D Q$ yang tertinggi menunjukkan bagian tubuh yang paling sering mengalami rasa sakit atau nyeri.

\section{E. Rapid Entire Body Assesment (REBA)}

Perhitungan Rapid Entire Body Assesment (REBA) adalah metode untuk menilai posisi kerja pada postur leher, punggung, lengan, pergelangan tangan, dan kaki. Metode ini fokus terhadap keseluruhan postur tubuh untuk mengurangi potensi terjadinya musculoskletal disorders pada tubuh pekerja (Sulaiman \& Sari, 2018). Skor 1 level risiko sangat rendah, skor 2-3 level risiko rendah, skor 4-7 level risiko sedang, dan skor 9-10 level risiko sangat tinggi (Suryadi \& Rachmawati, 2020).

\section{METODOLOGI}

Penelitian ini menggunakan metode penelitian eksperimental di proyek konstruksi pembangunan Jembatan Mlowo, Cs (Jembatan Nguter Sukoharjo). Data yang diperoleh dari hasil pengamatan langsung maupun wawancara dinalisis menggunakan kuesioner Cornell Musculoskeletal Discomfort Questionnaires (CMDQ) dan metode Rapid Entire Body Assesment (REBA). Alat dan bahan yang digunakan antara lain Worksheet REBA, Camera untuk mengambil gambar postur kerja, PC/Laptop, Perangkat lunak Microsoft Excel dan Autocad. Diagram alir penelitian disajikan pada Gambar 1. 


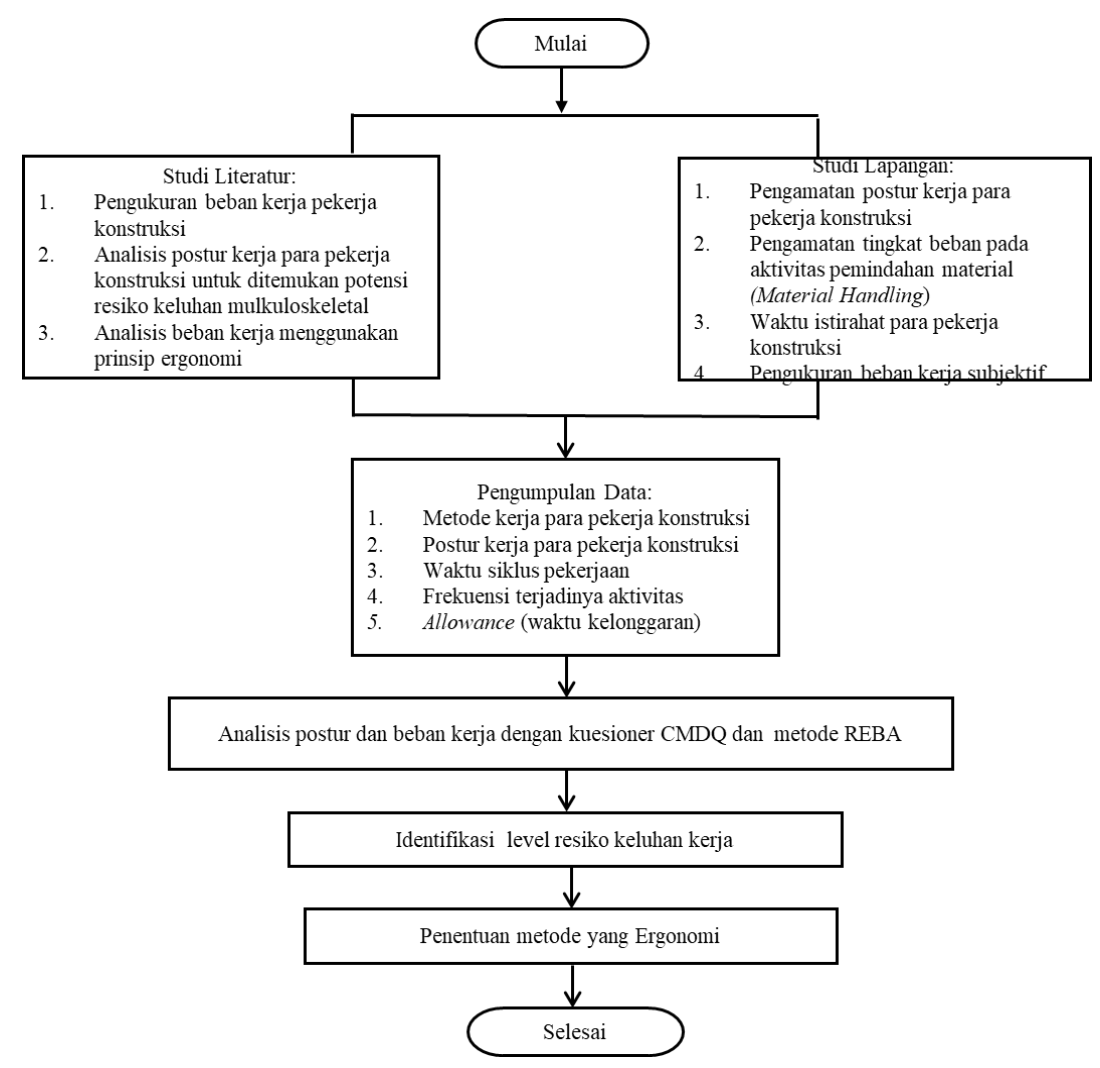

Gambar 1. Diagram alir penelitian

\section{HASIL DAN DISKUSI}

\section{A. Cornell Musculoskeletal Discomfort Questionnaires (CMDQ)}

Penelitian ini mengambil responden yang melakukan aktivitas di beberapa sub kegiatan proyek untuk menganalisis risiko postur kerja. Posisi para pekerja kurang baik sehingga dilakukan pengambilan data menggunakan wawancara dan kuesioner Cornell Musculoskeletal Discomfort Questionnaires (CMDQ) untuk mengetahui risiko bahaya musculoskeletal.

Pengumpulan data melalui wawancara dan kuesioner kemudian diolah untuk mengetahui bagian tubuh yang paling sering mengalami nyeri atau sakit. Pengolahan data kuesioner $C M D Q$ dilakukan berdasarkan bobot nilai sebagai berikut:

a. Frekuensi
1) Tidak pernah
$=0$
2) 1-2 kali seminggu
$=1,5$
3) 3-4 kali seminggu
$=3,5$
4) 1 kali setiap hari
$=5$
5) Beberapa kali setiap hari $=10$

b. Ketidaknyamanan
1) Sedikit tidak nyaman
$=1$
2) Agak tidak nyaman
$=2$
3) Sangat tidak nyaman
$=3$

c. Kemampuan bekerja
1) Tidak sama sekali
$=1$
2) Sedikit terganggu
$=2$
3) Sangat/sungguh mengganggu $=3$ 
Wawancara dilakukan pada responden di beberapa sub kegiatan proyek yang disajikan pada Tabel 1 .

Tabel 1

Identitas pekerja

\begin{tabular}{rcccl}
\hline No & Nama & Gender & Umur & \multicolumn{1}{c}{ SK } \\
\hline 1 & L1 & Laki-laki & 50 & Penulangan \\
2 & L2 & Laki-laki & 29 & Pemindahan baja \\
3 & L3 & Laki-laki & 35 & Pengecoran (menahan bak penuang) \\
4 & L4 & Laki-laki & 41 & Pemasangan bagesting \\
5 & L5 & Laki-laki & 32 & Pengecoran (mengalirkan) \\
6 & L6 & Laki-laki & 44 & Pemindahan girder \\
7 & L6 & Laki-laki & 30 & Pemindahan las listrik \\
\hline
\end{tabular}

Para pekerja memanfaatkan kelonggaran waktu yang berbeda selama jam kerja berlangsung. Ada yang sering beristirahat selama bekerja, ada yang terus menerus harus bekerja karena sulit untuk istirahat akibat aliran material yang mengharuskan pekerja tetap beraktivitas. 7 pekerja tersebut memiliki tingkat kenyamanan yang berbeda selama bekerja, ringkasannya disajikan pada Tabel 2.

Tabel 2

Ringkasan tingkat kenyamanan pekerja

\begin{tabular}{ccl}
\hline No & Nama & \multicolumn{1}{c}{ Ketidaknyamanan yang Dirasakan } \\
\hline 1 & L1 & Punggung, lengan atas, lengan bawah, lutut \\
2 & L2 & Bahu dan lengan \\
3 & L3 & Lengan atas dan bahu \\
4 & L4 & Lutut, paha, punggung, dan pergelangan tangan \\
5 & L5 & Lengan atas dan punggung \\
6 & L6 & Lengan atas, lengan bawah, bahu, dan punggung \\
7 & L6 & Bahu dan lengan atas \\
\hline
\end{tabular}

Berdasarkan tabel 2 setiap pekerja mengalami rasa sakit pada bagian tubuh yang berbeda. Pekerja L1 memiliki nilai $C M D Q$ yang relatif tinggi pada lengan atas, sebab membengkokkan baja tulangan agar sesuai dengan pola pembuatan bored piled secara manual. Pekerja L2 memiliki nilai $C M D Q$ yang relatif tinggi pada bahu, karena mengangkat beban tumpukan baja tulangan untuk dipindahkan dari truk ke lantai kerja. Pekerja L3 memiliki nilai $C M D Q$ yang relatif tinggi pada lengan atas, karena menahan beban selama 4-5 jam per hari selama pengecoran. Pekerja L4 memiliki nilai $C M D Q$ yang relatif tinggi pada punggung, karena duduk membungkuk selam jam kerja untuk membuat bagesting. Pekerja L5 memiliki nilai $C M D Q$ yang relatif tinggi pada lengan atas, karena mengayunkan cangkul untuk mengalirkan cor ke lantai kerja secara terus-menerus, dan sulit untuk istirahat sebab aliran cor yang terus-menerus mengalir otomatis dari truk mixer. Pekerja L6 memiliki nilai $C M D Q$ yang relatif tinggi pada lengan atas, karena melakukan pemindahan girder pada ketinggian. Pekerja L6 memiliki nilai $C M D Q$ yang relatif tinggi pada bahu, karena mengangkat las listrik secara berulang. Rangkuman hasil kuesioner CMD disajikan pada Tabel 3.

Tabel 3

Rangkuman hasil kuesioner Cornell Musculoskeletal Discomfort Questionnaires (CMDQ)

\begin{tabular}{ccl}
\hline No & Nama & Bagian Tubuh yang Paling Merasakan Nyeri \\
\hline 1 & L1 & Lengan atas \\
2 & L2 & Bahu \\
3 & L3 & Lengan atas \\
4 & L4 & Punggung \\
5 & L5 & Lengan atas \\
6 & L6 & Lengan atas \\
7 & L6 & Bahu \\
\hline
\end{tabular}

Berdasarkan Tabel 3, bagian tubuh yang paling sering dirasakan sakit oleh para pekerja adalah lengan atas. Maka hal ini perlu dilakukan perbaikan posisi kerja agar meningkatkan kenyamanan, mengurangi kelelaham serta meningkatkan produktivitas kerja. 


\section{B. Rapid Entire Body Assesment (REBA)}

Metode untuk mengetahui bagian tubuh yang memiliki keluhan akibat postur kerja salah, selanjutnya dilakukan penilaian postur kerja menggunakan data beban kerja yang disajikan pada Tabel 4

Tabel 4

Data beban kerja

\begin{tabular}{cll}
\hline No & \multicolumn{1}{c}{ Beban Kerja } & \multicolumn{1}{c}{ Bobot } \\
\hline 1. & Baja tulangan & $4,834 \mathrm{~kg} / \mathrm{m}$ \\
2. & Girder & 80 ton \\
3. & Las listrik & $3,5 \mathrm{~kg}$ \\
\hline
\end{tabular}

Beban di atas digunakan dalam aktivitas konstruksi. Terdapat 6 aktivitas yang dianalisis dalam penelitian ini, sebab memiliki tingkat risiko tinggi apabila dilakukan dalam jangka waktu lama. Penilaian postur kerja dari aktivitas pekerja konstruksi dapat dilihat pada Tabel 5.

Tabel 5

Penilaian postur kerja aktivitas konstruksi

\begin{tabular}{|c|c|c|c|c|}
\hline No & Gambar & $\begin{array}{c}\text { Skor } \\
\text { REBA }\end{array}$ & Level Risiko & Tindakan Perbaikan \\
\hline 1 & Penilaian postur kerja penulangan & 7 & Sedang & Perlu dilakukan perbaikan \\
\hline 2 & $\begin{array}{l}\text { Penilaian Postur Kerja pemindahan baja } \\
\text { tulangan }\end{array}$ & 10 & Tinggi & Harus segera dilakukan perbaikan \\
\hline 3 & Penilaian Postur Kerja pengecoran & 11 & Sangat Tinggi & Perlu saat ini juga dilakukan \\
\hline 4 & Penilaian Postur Kerja pemasangan bagesting & 7 & Sedang & Perlu dilakukan perbaikan \\
\hline 5 & Penilaian Postur Kerja pengecoran & 9 & Tinggi & Harus segera dilakukan perbaikan \\
\hline 6 & Penilaian Postur Kerja pemindahan girder & 12 & Sangat Tinggi & Saat ini juga dilakukan perbaikan \\
\hline 7 & Penilaian Postur Kerja pemindahan las listrik & 10 & Tinggi & Harus segera dilakukan perbaikan \\
\hline
\end{tabular}

Berdasarkan tabel di atas diketahui bahwa semua aktivitas menunjukkan risiko sedang, tinggi, maupun sangat tinggi. Ketiganya menuntut untuk dilakukan perbaikan, sebab dapat berisiko cedera, dan penurunan produktivitas akibat postur kerja yang salah atau postur kerja yang seharusnya menggunakan alat bantu tetapi hanya dilakukan secara manual. Hal seperti ini harus diperbaiki agar meningkatkan efisiensi kerja.

\section{KESIMPULAN}

Berdasarkan hasil analisis dan pembahasan dapat disimpulkan bahwa seluruh proses kerja pembangunan Jembatan Mlowo, Cs Nguter Sukoharjo yang dijadikan sampel pada penelitian memerlukan perbaikan kerja. Terbukti dari hasil penilaian dan analisis menggunakan kuesioner Cornell Musculoskeletal Discomfort Questionnaires (CMDQ) banyak bagian tubuh yang dirasakan sakit oleh pekerja selama melakukan aktivitasnya. Keluhan nyeri yang sering dirasakan pekerja didominasi oleh nyeri lengan tas. Lalu pada metode Rapid Entire Body Assesment (REBA) menunjukkan skor yang tinggi yang artinya harus dilakukan perbaikan pada sistem kerja pembangunan Jembatan Mlowo, Cs Nguter Sukoharjo agar tidak menimbulkan cedera ataupun keluhan muskuloskeletal akibat posisi kerja yang tidak sesuai.

\section{PENGHARGAAN}

Terima kasih kepada seluruh pihak yang telah membantu penelitian maupun pengolahan data penelitian, hingga terselesaikannya paper ini. penelitian ini tidak terlepas dari bimbingan Ibu Maria Puspita Sari, S.T., M.Sc., selaku dosen Teknik Industri Universitas Veteran Bangun Nusantara Sukoharjo. Pihak lain yang turut berkontribusi adalah BPPJN Jateng, PT Damai Citra Mandiri-PT Deltamarga Adyatama KSO yang telah memberikan ijin penelitian di pembangunan Jembatan Mlowo, Cs Nguter Sukoharjo. 


\section{DAFTAR PUSTAKA}

Dewi, L. T. (2017). Karakterisasi Keluhan Muskuloskeletal Akibat Postur Kerja Buruk Pada Pekerja Industri Kecil Makanan. Jurnal Ilmiah Teknik Industri, 15(2), 145.

Fathimahhayati, L. D., Amelia, T., \& Syeha, A. N. (2019). Analisis Beban Kerja Fisiologi pada Proses Pembuatan Tahu Berdasarkan Konsumsi Energi (Studi Kasus: UD. Lancar Abadi Samarinda). Jurnal INTECH Teknik Industri Universitas Serang Raya, 5(2), 100-106.

Hasrianti, Y. (2016). Hubungan Postur Kerja dengan Keluhan Muskuloskeletal pada Pekerja di PT. Markuri Internasional Indonesia Makassar (Vol. 4, Issue 1) [Universitas Hasanudin].

Internasional Labor Organization. (2014). Pengaruh Postur Kerja Terhadap Keluhan Muskuloskeletal. Gema Lingkungan Kesehatan, 17(1), 14-19.

Messah, Y. unit., Widodo, T., \& Adoe, M. (2013). Kajian Penyebab Keterlambatan Pelaksanaan Proyek Konstruksi Gedung di Kota Kupang. Jurnal Teknik Sipil, II(2), 157-168.

Pratam, P., Tannad, H., Nurprihatin, F., Ariyono, H. B., \& Sari, S. M. (2013). Identifikasi Risiko Ergonomi Dengan Metode Quick Exposure Check dan Nordicbody Map. Jurnal PASTI, 53(9), 1689-1699.

Pratama, T., Hadyanawati, A. A., \& Indrawati, S. (2019). Analisis Postur Kerja Menggunakan Rapid Office Strain Assessment dan CMDQ pada PT XYZ. Jurnal Ilmiah Teknik Industri UMS, 13(1), 1-7.

PT Safety Sign Indonesia. (2018). Cegah Cedera, Pekerja Harus Paham Panduan Manual Material Handling (MMH). 1-15. https://www.safetysign.co.id/news/369/Cegah-Cedera-Pekerja-Harus-Paham-Panduan-

Sulaiman, F., \& Sari, Y. P. (2018). Analisis Postur Kerja Pekerja Proses Pengeasahan Batu Akik Dengan Menggunakan Metode Reba. Jurnal Teknovasi, 3(1), 16-25.

Suryadi, I., \& Rachmawati, S. (2020). Work Posture Relations With Low Back Pain Complaint on Partners Part of Pt "X" Manufacture of Tobacco Products. Journal of Vocational Health Studies, 3(3), 126.

Tjahayuningtyas, A. (2019). FAKTOR YANG MEMPENGARUHI KELUHAN MUSCULOSKELETAL DISORDERS (MSDs) PADA PEKERJA INFORMAL. The Indonesian Journal of Occupational Safety and Health, 8(1), 1.

Verawati, L. (2017). Hubungan Tingkat Kelelahan Subjektif Dengan Produktivitas Pada Tenaga Kerja Bagian Pengemasan Di Cv Sumber Barokah. The Indonesian Journal of Occupational Safety and Health, 5(1), 51.

Widodo, L., Sukania, I. W., \& Angraeni, R. (2017). Analisis Beban Kerja Dan Keluhan Subjektif Pekerja Serta Usulan Perbaikan Pada Proses Pembuatan Batako. Jurnal Ilmiah Teknik Industri, 5(3), 179-190. 